\title{
Foundational Gender Theory for a Dangerous World: Intersectional Gender Seminar in the Fight against Rape Culture
}

\author{
Flavia Vidal ${ }^{1, *}$ and Tasha Hawthorne ${ }^{2}$ \\ 1 Brace Center for Gender Studies and English Department; Phillips Academy, 180 Main St., Andover, \\ MA 01810, USA \\ 2 English Department; Berea College; 101 Chestnut St., Berea, KY 40404, USA; Tasha_Hawthorne@berea.edu \\ * Correspondence: fvidal@andover.edu; Tel.: +1-978-749-4255
}

Received: 21 May 2017; Accepted: 24 August 2017; Published: 1 September 2017

\begin{abstract}
This paper focuses on a team-taught gender studies colloquium in the spring term of 2016 at Phillips Academy at Andover. Having heard the loud and clear message coming down from college campuses and being familiar with their harrowing statistics of gender-based violence and sexual assault, we knew that we must educate high-school students about gender theory, gender-based violence, and sexual-assault prevention as early as possible. The course introduced students to foundational texts in intersectional gender theory and key concepts as they are understood and used in critical interdisciplinary studies of gender. We explored how these concepts are taken up from different perspectives to address specific social problems, particularly rape culture-actions, events, and attitudes that normalize, trivialize, and highlight an overarching pattern of sexual assault, more often than not directed at women-and the implications of these critical approaches for thinking about and acting in the world.
\end{abstract}

Keywords: rape culture; intersectionality; panopticism

\section{Rationale/Introduction}

Since its inception, the Brace Center for Gender Studies has been at the forefront of Phillips Academy's initiatives to educate our students about gender. In 1996, Donna Brace Ogilvie, Abbot Academy alumnae class of 1930, provided a generous gift to Phillips Academy which enabled the establishment of the Brace Center for Gender Studies. To this day, the center functions as the only such resource at the secondary school level. While that gift was necessary, prescient, and foundational, as the rich 20-year history of the center attests to, it did not match either the multiple needs-intellectual, residential, personal, and institutional — of our diverse constituencies or our present mandate. With the passing of Ms. Ogilvie, in the 20th anniversary year of the Brace Center, and with new leadership at its helm, the Academy demanded a new iteration of the Center, one that enlarged its reach and impact. This colloquium was a case study to test the center's broad vision of academic scholarship informing and preparing students to understand "how we got here" and to engage their help in problem solving around issues of gender inequality. Because of all of the novel programming installed that year (2015-2016), students asked for a formal space wherein they could learn gender theory and understand the contemporary gender issues that affect them on a daily basis from an academic and a theoretical historical perspective. We wanted to capitalize on the center's momentum and give the gender conversation depth and breadth by increasing the intellectual content of the discussions and pointing out to students how this connects to their mundane, everyday experiences on campus and beyond, so as to help deconstruct rape culture, toxic masculinity, etc. We wanted to experiment with a final project/assessment that was a design-based challenge related to the students' campus experience 
of gender, merging the "theory and practice" ideas. Ultimately, we demanded that our students be active participants in their learning, problem solve creatively and collectively, and develop empathy for the school community they were about to leave behind by working together to make it better in the future.

In 2015, when we began our tenure as co-directors, the Brace Center had just hosted a secondary school conference on preventing gender-based violence and sexual assault; naturally, the nine recommendations from that conference formed our agenda for the 2015-2016 school year. From supporting survivors to providing bystander-intervention training to helping deconstruct rape culture, we had a lot to work with. We developed a variety of programs to address the issue, from a screening and discussion of Jennifer Siebel Newsom's documentary The Mask You Live In (Siebel Newsom 2015) and performances of the Arts Effect All-Girls Theater Company's SLUT: The Play, (Cappiello 2016) both of which were required for all our 9th graders, to a school-wide Take Back the Night march and vigil. Still, as productive as these co-curricular initiatives proved to be, we both felt we needed to do something with the currency that is most valued by Andover students: a direct connection to classroom learning. Our graduate training in English and Comparative Literature doctoral programs, with a specific focus on intersectional gender issues, together with a successful model of colloquia for seniors developed and implemented by like-minded colleagues over the years, brought us naturally to the idea of a capstone spring colloquium on gender theory to be offered to our most capable feminist students, that is, students who had previously demonstrated the highest levels of understanding and practice of gender equity and inclusion in their Andover careers. Titled Foundational Gender Theory for a Dangerous World: Intersectional Gender Seminar in the Fight against Rape Culture, the course introduced students to foundational texts in intersectional gender theory, teaching them key concepts in critical interdisciplinary studies of gender. The reading list included authors such as Gloria Anzaldúa, Cherríe Moraga, Judith Butler, Michel Foucault, Sigmund Freud, Melissa Harris Perry, Patricia Hill Collins, bell hooks, Audre Lorde, Fatema Mernissi, Laura Mulvey, E. Anthony Rotundo, Gayle Rubin, and Hortense Spillers. We explored how concepts emerging from these theorists can be taken up from different perspectives to address specific social problems, particularly rape culture, and the implications of these critical approaches for thinking about and acting in the world. Colleagues from a variety of departments gave lectures in a pilot course that functioned as a group independent project capped at six students (two who identified as male, four as female) in their last trimester at Andover. This academic year, the course is being offered again as a senior elective, with the regular maximum enrollment of fifteen, and the registration filled up immediately. The rest of the paper highlights how the students understood the key themes covered by the course, how they were challenged by them too, and, ultimately, how such gender theories play out in their daily lives.

\section{Understanding the Roots of Early Feminist Discourse and the Need for Intersectionality}

The first obvious challenge was for students to understand the various levels of feminist discourse and kinds of feminisms from a historical, non-intersectional viewpoint (or from the perspective of what amounted to intersectionality before Kimberle' Crenshaw coined the term). For most of these students, intersectionality, or the interconnected nature of identities like race, class, gender, and sexuality, and how these overlapping social categories create independent and dependent systems of oppression, had been a familiar concept for years, both in their classroom and personal experiences. Thus, when we assigned Paul Fry's Yale Open Source lecture "The Classical Feminist Tradition" (Fry 2016) as both a history lesson and starting point for the course, one of our students had this to say in response to his points about Virginia Woolf's A Room of One's Own: "The place that we seem to be starting from is that a person's context is very important to their writing - the idea of competitive identity. It seems very common now (intersectionality) but this lecture identified the difference between class or gender and NOT intersectionality" (Brianna 2016). This was one of the big challenges that was laid out for us: how to help the students differentiate what some authors or theories posited from the responses/critiques to said authors/theories_-given that, for the most part, they would not have time to read more than 
a handful of sample material. In this particular case, what they needed to know was encapsulated in Woolf's famous statement that "a woman needs money and a room of her own if she is to write," (Woolf 2005). Woolf herself was being intersectional (connecting gender and class), and people who criticized her were the ones who said that one can be only a Marxist or a feminist (Alix 2016).

\section{Internalizing Compulsory Heterosexuality}

The New England boarding-school student world was deeply affected, emotionally and psychologically, in May 2014 when 15-year-old Chessy Prout accused senior Owen Labrie of sexually assaulting her as part of the "senior salute" tradition at St. Paul's School (Bidgood and Motoko 2015). The fallout that ensued is almost a textbook case for the conflation of panopticism, French philosopher Michel Foucault's theory of self-regulation and surveillance based on the idea of a disciplinary society of surveillance, and masculine performativity, how gender is reified by the ways in which a person performs or acts out what is expected of their gender (to use Judith Butler's concept) which we were trying to get at, in particular if we add the context of privilege in which the events played out, with Labrie's wealthy friends' fathers from the soccer team coming together to pay for his legal defense. At the heart of the issue, as our students eventually concluded, was the unspoken fear that Labrie himself, a Harvard-bound honorary member of the privileged male athlete elite of New England boarding schools - in other words, someone who exemplifies the pinnacle of achievement for many of our students - would go from metaphorical to literal "fuckboy" once he got to jail, in an ironic twist performing the role that had been Prout's during their encounter.

In the wake of the St. Paul's case and other incidents at different high schools and colleges, the Brace Center was not the only constituency at Andover preoccupied with educating our students about preventing gender-based violence and sexual assault; the matter was being taken seriously at high levels of the school's administration. However, our students kept expressing frustration with the ways in which the sessions organized with such goals were conducted and, in particular, with the euphemistic language of "healthy relationships" that left many students confused as to what was actually being discussed. Thus, our session on Foucault was illuminating; it didn't take long for students to understand how "discourse affects how we perceive and how we engage with sex" (Jack 2016) and to relate one of Foucault's fundamental questions to their everyday campus reality: "Did the critical discourse that addresses itself to repression come to act as a roadblock to a power mechanism that had operated unchallenged up to that point, or is it not in fact part of the same historical network as the thing it denounces ... ?" (Foucault 1978). At this point, they were even able to connect this idea back to panopticism through the mandated conversations that dormitory house counselors have to have with students before allowing them to receive visitors of another gender into their rooms-the very problematic system of parietals, or opposite-gender room visitations, on our campus, which consume an extraordinary amount of time, energy, and angst from students and adults alike. As the students quickly concluded, the much-touted "healthy-relationships" conversations, within a highly-variable and not well-administered system of parietal-granting, ran the real risk of helping not in the "lessening of prohibitions, [but] as a more devious and discreet form of power" (Foucault 1978), even when this imposition of power was not necessarily a conscious choice on the part of the administration.

\section{Identifying Patriarchy and Capitalism: Fetishizing and Reaffirming Penis Envy}

But what are the origins of some of the hegemonic power structures we were contending with? Rubin's seminal essay "The Traffic in Women" (Rubin 1975) helped provide some of the historical, psychological, economic, and anthropological background on intertwined systems of oppression. The main takeaway from that discussion was, "The kind of woman necessary in a system of exchange is the one with passive sexuality" serving both patriarchy and capitalism (Liam 2016). From there we arrived, after brainstorming with students, at modern traditions such as "promise rings, wedding ceremonies, debutante ball, quinceañera", and, in our specific Andover context, the commencement 
tradition of girls wearing white dresses and carrying a red rose. ${ }^{1}$ But what happens when such passive sexuality is not displayed by women who are supposed to function as commodities? Or worse, when we have a more radical challenge to the binary gender roles upon which many of these systems of patriarchal and capitalistic exchange are based? Our students concluded that the first question's answers vary in kind, though they ultimately all rise from "male fragility" —or self-inflicted penis envy, to use Freud's own term. From "feminazi" to "man hater" to different modalities of slut shaming, there are many ways in which women who attempt self-expression, agency, and control of their sexuality are slandered. Within the specific context of the sexual encounter as defined by Freud, the taboo of the Oedipal complex coupled with the male desire for a debased object as the only provider of his full satisfaction seems to make the very idea of sexual pleasure based on consent-leading to an affirmation of both parties' desires-unattainable from the male perspective. In the words of one of our students, "Within the context of PA, this manifests itself in the distinction between someone who is 'wife material' and 'hook-up material'" (Emily 2016).

On the second question, we were intrigued by the possibilities that a more fluid expression of gender roles brings to the issue. The students posited that a genderless (not sexless) social structure could be the only possible scenario to do away with patriarchal and capitalist dominant systems. It is quite ironic that we discussed the political gains of the LGBTQ+ movement in this context, with an example brought up of even then-candidate Trump's criticism of North Carolina's transgender bathroom law (Forest et al. 2016), together with his famous invitation to Caitlyn Jenner to use any restroom she wanted in Trump Tower (Gittleson 2016). Of course, his administration's recent revoking of the protections for transgender students that he publicly supported as a candidate reaffirms our students' instincts that patriarchy and capitalism, as systems designed to protect themselves and their structures, will quickly repress any challenges to traditional binary gender expressions (Peters et al. 2016).

\section{Recognizing Agency, or the Lack Thereof: Performing (White) Post-Feminism}

Without a doubt (and understandably so), the most difficult theory for our students to grasp was Butler's notion of performativity in gender discourse. Precocious they were, but they were also high schoolers that were still developing more abstract thinking skills. That said, they plowed through "Critically Queer" (Butler 1993), asking insightful questions and connecting their understanding to earlier texts, especially Foucault's. We did not realize how much they had actually learned until the following week, when they were introduced to the notion of post-feminism and they were quickly able to relate it to different levels of gendered performative discourse. Starting from ideas like "Gender is always relational. You are a certain gender in relation to a certain gender" (Jack 2016), they identified the problematic at the heart of post-feminism: certain portrayals of "empowered" women (as in, for example, women who appropriate negative behaviors traditionally associated with masculinity, like violence or male subjugation, or those who equate agency to sexualizing their own bodies for male consumption) "undo" a discourse previously deemed feminist and substitute it with post-feminist performativity, getting stuck in a relational loop from which it is hard to disentangle oneself. To avoid the trap, we needed to guide them out of the mistress house of white feminism.

\section{Expanding Feminisms, Deconstructing Theory, and Embodying Activism: Reading This Bridge Called My Back}

Our sessions on intersectional feminism and, later, black feminism allowed us to push many of the early conversations forward and, at the same time, complicate our students' nuanced understanding of

1 This tradition goes back to the old Abbot Academy and its commencement ceremony; since 2013, after a grassroots student feminist movement protested the practice, all students carry roses at commencement. Founded in 1828, Abbot Academy was one of the oldest all-girls, independent, preparatory day and boarding schools in New England. Located less than a mile away from its brother school, Phillips Academy, it merged with the all-boys school in 1973. To this day, however, and depending upon which sources one cites, the term "merger" might be used. For others, the term "absorbed" is more apt. 
their own epistemological identities as agents of social change. Those started with a deconstruction of the value of theory in academic discourse through a close reading of sections of Moraga and Anzaldúa's 1981 canonical anthem of intersectional feminism, This Bridge Called My Back: Writings by Radical Women of Color (Moraga and Anzaldúa [1981] 2015). The text provided the students with a clear "articulation of something experienced versus something observed" (Kaela 2016), giving them a necessary bridge to the a-ha moment where they were able to conclude that "traditional academia is inaccessible to those who need feminism the most" (Kaela 2016). To get there, though, they needed to wrestle with the clarion call in Lorde's seminal essay “The Master's Tools Will Never Dismantle the Master's House," (Lorde and Clarke 2007) which illuminated, for the first time in the term, some stark differences in our students' personal engagement with the course content. It was interesting to observe one particular student's reaction to Lorde's essay: Usually one of our most astute and nuanced readers, she quickly understood that Lorde warns us about the difference between effecting " ${ }^{*}$ change ${ }^{*}$ [in] preexisting structures as opposed to being able to construct new ones" (Alix 2016). However, she was genuinely wary of the need to dismantle the master's house. And her reaction puzzled us at first, until her own reflection on her personal experience of Andover as the "master's house" gave us the key to the mystery: As a second-generation immigrant with a family narrative undeniably grounded on the model-minority trope and with a strong record of academic and extracurricular achievements at Andover, she felt that she had, deservedly, earned her place in the privileged master's house. Why would she want to dismantle it? Wouldn't it be better, as she put it, to use her hard-earned privilege to help create spaces to benefit those without it, improving access to the house instead of bringing it down? (Emily 2016). But as another student was quick to point out, therein lies the inherent problem of individualized forms of feminism, the kinds of "lean ins" popularized by Sheryl Sandberg that can ultimately benefit only those with already some form of privilege and power (Sandberg 2013). That particular brand of white feminism is exactly what This Bridge Called My Back, as well as the countless feminists of color it has inspired, have warned us against. The solution? Coalition building for social change. And since we did agree that the "[f]ramework of theory is similar to the master's house ... [so to] change the nature of theory is to construct your own house" (Liam 2016), we envisioned a final capstone project for the course that would allow the students to integrate the course content, outside research, and a praxis-oriented outcome while fostering intersectional feminist goals within the Andover community.

\section{Conclusions and Final Projects}

In the final month of the class the students needed to identify and complete a final class project. Those topics were easily generated when the students pondered the following question: "What is it that you are angry about, and what do you want to do about it?" Working in groups, each honed in on a specific residential component of the school that demanded a keener eye towards gender equity. Coincidentally, these were all areas to which our school administration has been paying attention this year, but the papers that the students wrote for the course all provided not only a deeper analysis of the gender dimensions of the issue at hand, but also a more rigorous set of protocols to eliminate its discriminatory aspects. The first group rewrote the sexual misconduct section of the Andover Blue Book, the school's official document that outlines expectations and policies with respect to academics, community governance, and behavior. They wrote nuanced language that acknowledged the oftentimes fraught and scary situations that ensue as a result of forced, unhealthy, or unknowing choices. Additionally, they were clear and explicit about what actions and behaviors constitute rape, consent, and sexual misconduct. The second group created a template for a rigorous selection and training program for student proctors and prefects in our dormitories. In the past, the selection of these student leaders has been based either on the popularity of the individual or a faint hope that the student would abide by and enforce the school rules. Instead, and rightfully, these students wanted to change the parameters of the job itself. They demanded more accountability, more direct feedback from the adults who have entrusted them with the job, and more education. They created a three-unit proctor/prefect reader including a unit summary, specific articles, essential questions, and a theoretical 
basis for the unit itself. The final group wrote a proposal for steps that needed to be taken prior to the piloting of the school's first all-gender dormitory. Some of their recommendations included clarity in terminology and intent, as well as new policies guaranteeing fairness for students and faculty interested in such a living environment.

While we understand that we have had the privilege of working at an institution with a plethora of resources, we also know that one of the best ways to engage students' in problem solving around issues of gender inequality is to merge the scholarly tradition of the Brace Center with our new access to the students' full experience on campus. This gender studies colloquium was just one step in that direction.

Acknowledgments: Our participation in the conference was funded by a generous grant from the Abbot Academy Association, continuing Abbot's tradition of boldness, innovation, and caring. We are grateful to all our colleagues who generously gave their time and expertise to this colloquium, making it possible: Thomas Kane, Elizabeth Meyer, Anthony Perry, Patricia Har, Emma Staffaroni, Sofia Tirado, Danica Fisher, David Fox, E. Anthony Rotundo, and Adrian Khactu; to our department chair, Stephanie Curci, and dean of studies, Patricia Russell, who supported our idea from its inception; to Elizabeth Tompkins at the Oliver Wendell Holmes library, who graciously helped to check all our references; and most importantly, to the six wonderful students who embarked with us on this challenging yet profoundly rewarding intellectual journey.

Conflicts of Interest: The authors declare no conflict of interest. Students' names have been changed to protect their privacy.

\section{References}

Alix (student). 2016. Class Notes-03/22/2016. Foundational Gender Theory for a Dangerous World: Intersectional Gender Seminar in the Fight against Rape Culture, Phillips Academy, Andover, MA, USA, 22 March 2016.

Bidgood, Jess, and Rich Motoko. 2015. Rape Trial Puts Focus on Culture of a School. New York Times, August 19. Available online: libraries.state.ma.us/login?gwurl=http://go.galegroup.com/ps/i.do?p=SPN.SP24\&sw= w\&u=mlin_n_phillips\&v=2.1\&id=GALE\%7CA425896306\&it=r\&asid=c28dfaadffa03249968b2d208325051f (accessed on 28 April 2017).

Brianna (student). 2016. Class Notes—04/11/2016 and 05/23/2016. Foundational Gender Theory for a Dangerous World: Intersectional Gender Seminar in the Fight against Rape Culture, Phillips Academy, Andover, MA, USA, 23 May 232016.

Butler, Judith. 1993. Critically Queer. GLQ: A Journal of Lesbian and Gay Studies 1: 17-32.

Cappiello, Katie. 2016. SLUT: The Play. Andover: Phillips Academy.

Emily (student). 2016. Class Notes-04/05/2016. Foundational Gender Theory for a Dangerous World: Intersectional Gender Seminar in the Fight against Rape Culture, Phillips Academy, Andover, MA, USA, 5 April 2016.

Forest, Daniel, Timand Moore, and Pat McCrory. 2016. An Act to Provide for Single-sex Multiple Occupancy Bathroom and Changing Facilities in Schools and Public Agencies and to Create Statewide Consistency in Regulation of Employment and Public Accommodations. H.B. 2, General Assembly of North Carolina. 2nd Extra Session (N.C. 2016). Available online: http:/ / www.ncleg.net/sessions/2015e2/bills/house/pdf/h2v4. pdf (accessed on 28 April 2017).

Foucault, Michel. 1978. We “Other Victorians". In The History of Sexuality. New York: Random House, vol. 1, pp. 1-13.

Fry, Paul. 2016. The Classical Feminist Tradition. New Haven, CT, USA: ITunesU. Available online: http: / / oyc.yale.edu/english/engl-300/lecture-20 (accessed on 22 March 2016).

Gittleson, Ben. 2016. Donald Trump OK with Caitlyn Jenner Using Any Bathroom in His Tower. ABC News, April 21. Available online: http:/ /abcnews.go.com/Politics/donald-trump-caitlyn-jenner-bathroom-tower/ story?id=38566263 (accessed on 28 April 2017).

Jack (student). 2016. Class Notes—05/09/2016. Foundational Gender Theory for a Dangerous World: Intersectional Gender Seminar in the Fight against Rape Culture, Phillips Academy, Andover, MA, USA, 9 May 2016.

Kaela (student). 2016. Class Notes—05/02/2016. Foundational Gender Theory for a Dangerous World: Intersectional Gender Seminar in the Fight against Rape Culture, Phillips Academy, Andover, MA, USA, 2 May 2016. 
Liam (student). 2016. Class Notes—04/04/2016. Foundational Gender Theory for a Dangerous World: Intersectional Gender Seminar in the Fight against Rape Culture, Phillips Academy, Andover, MA, USA, 4 April 2016.

Lorde, Audre, and Cheryl Clarke. 2007. Sister Outsider: Essays and Speeches. Berkeley: Crossing Press.

Moraga, Cherríe, and Gloria Anzaldúa. 2015. This Bridge Called My Back: Writings by Radical Women of Color, 4th ed. Albany: SUNY Press. First published 1981.

Peters, Jeremy W., Jo Becker, and Julie Hirschfeld Davis. 2016. Trump Rescinds Rules on Bathrooms for Transgender Students. New York Times, February 22. Available online: https://www.nytimes.com/2017/02/22/us/ politics/devos-sessions-transgender-students-rights.html (accessed on 28 April 2017).

Rubin, Gayle. 1975. The Traffic in Women: Notes on the 'Political Economy' of Sex. In Toward an Anthropology of Women. Translated by Rayna R. Reiter. New York: Monthly Review Press.

Sandberg, Sheryl. 2013. Lean in: Women, Work, and the Will to Lead. New York: Knopf.

Siebel Newsom, Jennifer. 2015. The Mask You Live In. New York: Virgil Films and Entertainment.

Woolf, Virginia. 2005. A Room of One's Own. Orlando: Harcourt.

(C) 2017 by the authors. Licensee MDPI, Basel, Switzerland. This article is an open access article distributed under the terms and conditions of the Creative Commons Attribution (CC BY) license (http:/ / creativecommons.org/licenses/by/4.0/). 